\title{
Circular Economy Mainstream: an Analysis of Master Thesis and Dissertations
}

\section{Mainstream da Economia Circular: uma Análise de Teses e Dissertações de Mestrado}

\author{
EDSON LUIS KUZMA ID
}

SIMONE SEHNEME

\section{Abstract}

The specialized scientific production resulting from master's and doctoral research works and reports, indicates existing targets and advances in specialized research in circular economics. This study aims to develop a systematic literature review that highlights the thematic axes and areas of interest in the field of circular economics that are addressed in highly specialized studies, the result of master's and doctoral studies. 11 predominant areas of interest of researchers in theses and dissertations are identified, denominated as categories, and other 5 smaller areas, denominated study subcategories. A framework is proposed that organizes the various identified themes and provides a holistic understanding of the insertion of the circular economy in the master's and doctoral programs. The study contributes to the theory by mapping, describing and organizing in a logical way the thematic paths and axes that the theses and dissertations take when describing and addressing different associated research problems. From a practical point of view, this study can assist decision makers and policy makers in raising awareness and knowledge about possible fields of action regarding its implementation.

Keywords: Circular Economy; Gray Literature, Theses; Dissertations. 


\section{RESUMO}

A produção científica especializada resultado de trabalhos e relatórios de pesquisas de mestrado e doutorado, indicam alvos existentes e avanços das pesquisas especializadas em economia circular. Este estudo tem por objetivo desenvolver uma revisão sistemática de literatura que evidencia os eixos temáticos e áreas de interesse no campo da economia circular que são abordados em estudos de alta especialização, frutos de trabalhos de mestrado e doutorado. São apontadas 11 áreas predominantes de interesse de pesquisadores em teses e dissertações, denominas como categorias, e outras 5 áreas menores, denominas de subcategorias de estudo. Propõem-se um framework que organiza os diversos temas identificados e fornece um entendimento holístico sobre a inserção da economia circular nos programas de mestrado e doutorado. O estudo contribui para a teoria ao mapear, descrever e organizar de forma lógica as vias e eixos temáticos que as teses e dissertações tomam ao descrever e abordar diferentes problemas de pesquisa associados. Do ponto de vista prático, este estudo pode auxiliar tomadores de decisões e formadores de políticas na conscientização e conhecimento sobre os campos possíveis de ação quanto a sua implementação.

Palavras-chave: Economia Circular; Literatura Cinzenta, Teses; Dissertações.

\section{INTRODUCTION}

Circular Economy (CE) emerged as an economic model focused on promoting the conscious and optimized use of resources by retaining value through prolonged use, reducing or eliminating waste generation, closing production in cycles, with minimal or without loss of resources and energy (Souza Junior et al., 2020). The approach contrasts the traditional production and consumption systems that consist of the logic of extracting, using and discarding. It aligns with the assumptions of sustainability and sustainable development by proposing production alternatives that maximize the usefulness of resources already inserted in production cycles and avoid the withdrawal of virgin resources from the environment (Fernandes et al., 2020). This objective is operated by decoupling economic growth from the continued need for resource exploration, which inhibits 
the generation of consequences such as environmental stress and accelerating the depletion of essential resources for society (Bocken et al., 2016; Nubholz, 2018).

The advancement in the field of CE makes up several initiatives by decision makers and policy makers. Theoretical and empirical studies have contributed in fields such as circular business models (Hoffmann, Morais, \& Teodoro, 2019), facilitators (Boer et al., 2020), barriers (Guldmann \& Huulgaard, 2020), circularity indicators (Heisel \& Rau-Oberhuber, 2019), policies (Völker, Kovacic, \& Strand, 2020), implementation methodologies (Chen et al., 2020), innovation (Pieroni, McAloone, \& Pigosso, 2019), interface with sustainability and sustainable development (Sverko Grdic, Krstinic Nizic, \& Rudan, 2020). The variety of fields and possible areas for exploration, the diversity of the phenomenon in the field, as well as the advances in the context of companies and policies for the circular economy make the theme recurrent and current (Lieder, Asif, \& Rashid, 2020). The field is emerging and pulverized on several fronts of exploration.

From a theoretical point of view, the field demands definition and clarification to enable the consolidation of the circular economy (Geissdoerfer et al., 2017). The justification for this research is based on providing an answer to the following key question: what existing targets and what advances does specialized research in circular economics, restricted to theses and dissertations, provide for progress in the field?

This study develops a systematic literature review that highlights the thematic axes and areas of interest in the field of circular economics that are addressed in highly specialized studies, the result of master's and doctoral studies. 11 predominant areas of interest of researchers in theses and dissertations are identified, denominated as categories, and other 5 smaller areas, denominated study subcategories. The themes are explored based on the frequency of their occurrence in the research and arranged in a theoretical model that allows viewing the broad panorama of the field's behavior. A framework is proposed that organizes the various identified themes and provides a holistic understanding of the insertion of the circular economy in the master's and doctoral programs. 
The originality of this work derives from the effort to map, understand and describe the articulation of the different approaches that the circular economy receives in highly specialized studies, related to dissertation and thesis documents. Several recent reviews add knowledge to the field by pacifying and promoting directions for future advances, as in the studies by Acerbi and Taisch (2020), Bag and Pretorius (2020), Bansal et al., (2020) and Hussain and Malik (2020). The choice of gray literature, limited to theses and dissertations, was made in order to seek to understand which themes are studies in deep research, the result of undergraduate internships and training of specialists at master and doctoral level. Peer-reviewed articles and other gray literature documents are more common. Therefore, the development of a systematic review of theses and dissertations presents a still unexplored panorama in depth, an issue that is addressed in this research.

The study is structured in sections. In addition to the introduction, in the second section there is a theoretical research framework. The third section describes the research procedures. The fourth section presents the results of extracting the mapped data. The fifth section provides an analysis of the themes. The sixth section discusses the main findings of the study and presents the integrated framework of the themes. The seventh section concludes the study and points out limitations.

\section{THEORETICAL FRAMEWORK}

The circular economy is defined as an economy model that is restorative and regenerative in its essence, which aims to maximize utility and the permanence of resources in production cycles, a concept widely disseminated by the Ellen MacArthur Foundation (EMF). Its principles are based on three fundamental aspects: i) to preserve and improve the use of natural capital, ii) to optimize the utility and yield of resources, iii) to promote the effectiveness of productive systems (EMF, 2015). The paradigm shift in the logic of production towards circular and more sustainable processes in a temporal perspective aims to reduce the consumption of virgin resources, maintain resources in productive systems, add value through use, close and narrow resource cycles to prolong their 
usefulness (Geissdoerfer et al., 2017). The incorporation of circular practices is especially promising for manufacturers, with the aim of reducing the need for new resources and the generation of waste from their commercial activities. In a fully circular economy, there is no generation of waste, since resources not used in the production process must be reinserted in other stages of production or destined for the manufacture of other products (Lieder, Asif, \& Rashid, 2020).

The circularity of resources increases the longevity of their use, dramatically decreases emissions and allows the permanence of resources and the reduction of losses due to waste (Konietzko, Bocken, \& Hultink, 2020). Business models based on circular logic receive increasing attention from industries and policy makers as a way of promoting economic development, sustainability in the use of resources and encouraging the protection of the natural environment (Chen et al., 2020). Practices aligned with EC, such as restoration, regeneration, recycling and reuse, promote the creation and transition to circular business models and the development of processes and products that allow resources to remain in the production system (Fellner \& Lederer, 2020; Pereno \& Eriksson, 2020). The system may face difficulties and barriers to its implementation, such as high initial transition costs, lack of cooperation between suppliers, disaggregation of the supply chain, weaknesses in the necessary skills, long-term results and high process costs (Pla-Julián \& Guevara, 2018; Jaeger \& Upadhyay, 2020).

Circularity can be measured and analyzed at the micro level (products, components, materials), meso level (inter firm, supply chain, industrial parks) and macro level (governments, countries, policies) (Ghisellini et al., 2016; Saidani et al., 2019). Different actions can be understood with impacts at different levels, since the activities may have a restricted scope according to their objective.

At the micro level, discussion and exploration of topics such as circular business models and life cycle assessment are common. The theme, although approached by different areas of knowledge, receives increasing attention for research in the area of engineering and business. The focus given by the various sub-areas of engineering aims to improve processes, the use of materials and energy, product planning to enable the reuse of materials and components 
after use, among others. In the management area, the concern is with the proposition of businesses aligned with the principles of circular economy and innovation for the circular transition (Bansal et al., 2020). The meso level can direct attention to resource efficiency and reuse, both practices that transmit value throughout the supply chain. The residues and resources not useful for a given process can be used in another, which adds value and fulfills the purpose of permanence of the resources in the production cycles (Bracquené, Dewulf, \& Duflou, 2020). At the macro level, policies for the circular economy and waste management are relevant and current issues. The incentive to implement circular practices is carried out by the institution of regulations at the government level, which define roles and assign responsibilities in the transition to the circular model of economy. Throughout the world, especially in European countries, China and Japan, policies are advanced and set goals for achieving minimum circularity standards for the coming years. Waste management is a relevant topic not only at the company level, but also at the macro level. The destination of waste with mitigation of environmental impact is a challenge for governments, especially with the insertion of the possibility of generating value with useless or waste materials. The residues can be transformed back into resources for reinsertion in the production cycle (Morseletto, 2020). The different initiatives for the circular economy must be explored and articulated, from a theoretical and practical point of view, so that opportunities are seized and alternatives are generated for different products and services. This fosters the transition to a circular economy on several fronts and accelerates its insertion in business and government policies.

\section{MeTHOD}

The method used in this research is a systematic literature review based on masters and doctoral dissertations and theses. The review was developed according to Tranfield et al. (2003) and the process is summarized in three stages, as shown in Figure 01. Schopfel and Prost (2020) point out that the percentage of articles that mention gray literature, which includes theses and dissertations, is relatively low, varying around $0,05 \%$ of the total materials used 
in academic research. However, its use is upward considering the trajectory from 1999 to 2018, with reference to the average growth of $5 \%$ per year. Its scope includes a wide variety of sources and forms of operation including Google, Google Scholar and university repositories as the main sources of specialized search in the field.

In the first stage, strings were defined and searches were performed on the databases. The bases used were the portal of the Brazilian Digital Library of Theses and Dissertations (BDTD) (URL http:// bdtd.ibict.br/vufind/), which integrates the information systems of theses and dissertations existing in teaching and research institutions from Brazil, to survey documents produced in the Brazilian context, and Google Scholar (URL https://scholar.google.com), to identify research and production of dissertations and theses in the global context. In the first, the string "circular economy" was used, with a return of 68 papers. In Google Scholar, the string "circular economy" was used, in the AND combination with "thesis" and "dissertation". The return was 18,600 results. The final search was carried out on August 8 and 9, 2020, without any chronological restrictions. The strings were identified in the title, summary, keywords and content.

As the search on Google Scholar returned a significant amount of results, we stratified and identified the relevance of the works for inclusion in the review. The preliminary examination of the research results indicated a drastic reduction in the utility and link to the scope of the study from the first 500 results, tending to zero the number of studies used. However, to certify the inclusion of all possible studies in the review, the first 1,000 results were evaluated. This goes beyond what was recommended by Haddaway et al. (2015) and Schopfel and Prost (2020), who recommend the inclusion of 200-300 results ordered by relevance for systematic reviews that use gray literature. In the end, the initial sample was 1,068 studies.

In the second stage, the preliminary reading of the works was carried out. The materials were evaluated by reading the title, abstract, keywords and the format / type of manuscript. The following exclusion criteria were adopted: i) works with a different format or type to the thesis or dissertation, ii) duplicate or redundant studies (only one of the studies found was considered), iii) studies published in a summarized format, iv) inability to locate the document file in 
full online, v) studies written in a language other than English or Portuguese, vi) studies that do not address circular economics or whose focus is not aligned with the scope of the research. No segmentation criteria were used based on the study area or methodology, including theses and dissertations from all possible areas and with the most varied methodological approaches. After applying the exclusion criteria, a final sample of 108 papers included for analysis was obtained, with 83 master's dissertations and 25 doctoral theses.

The third stage comprises the extraction of results and categorization based on theoretical arguments. The theses and dissertations were explored in order to identify information relevant to the characterization of the theme and studies and to define analytical categories. The documents were retrieved and analyzed for the tabulation of bibliometric information, such as authorship, year of publication, work orientation, university to which the thesis or dissertation is linked, area of knowledge, host country, applied sector, concept of circular economy adopted as guiding the research, level of implementation of the circular economy, objective, methodology, main results, limitations and recommendations, among other information. After the survey of the descriptive information that the results showed, analytical categories were defined to conduct the in-depth analysis of the results, demonstrating the prospects and possibilities for advancing the theme based on the limitations of previous studies.

The key themes of the analytical categories for the development and contextualization of the insertion of the circular economy in the context of the master's and doctoral programs took place from the visualization of the articulation of the areas and the direction that the progress of the field demonstrates. The data were analysed through a dynamic process of definition, classification, categorization and reading of the existing relationships. No coding of any kind already described in other review studies was adopted to promote novelty in the arrangement between themes and categories. After the data and analysis units were refined, the theoretical arguments were arranged and organized to generate confluence on the logic of the studies. From the arguments discussed, perspectives are drawn for advances in future studies based on the scope of the thesis or dissertation format, in a holistic way. 
The general procedures that guide the stages of carrying out the review are presented in Figure 01, shown below.

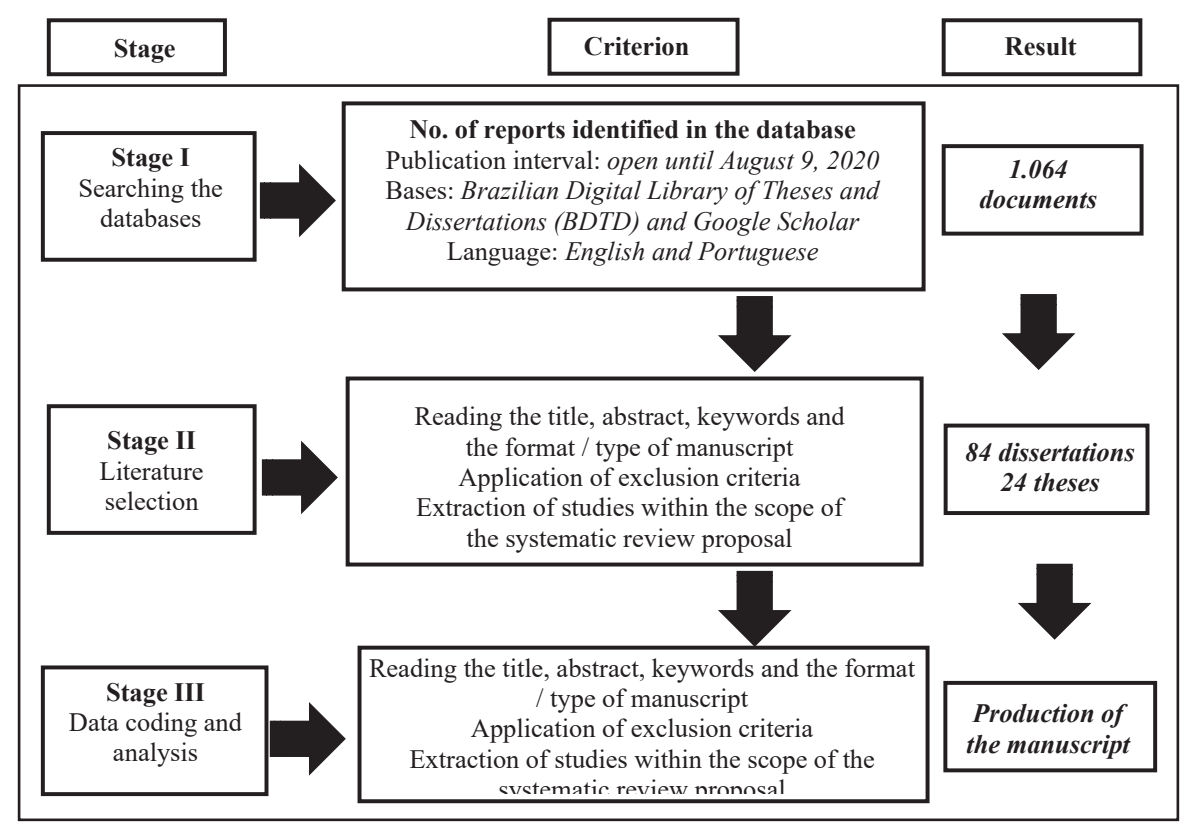

Figure 01. Flowchart of the procedures for carrying out the review

\section{STRUCTURAl ASPECTS OF REVISED ARTICLES}

The systematic review identified 108 grey literature documents on circular economics, with 83 master's dissertations and 25 doctoral theses. The frequency of documents registered over time reveals that the topic has followed the evolution of the advances in regulations, practices and other peer-reviewed publications. Figure 2 shows the frequency. 


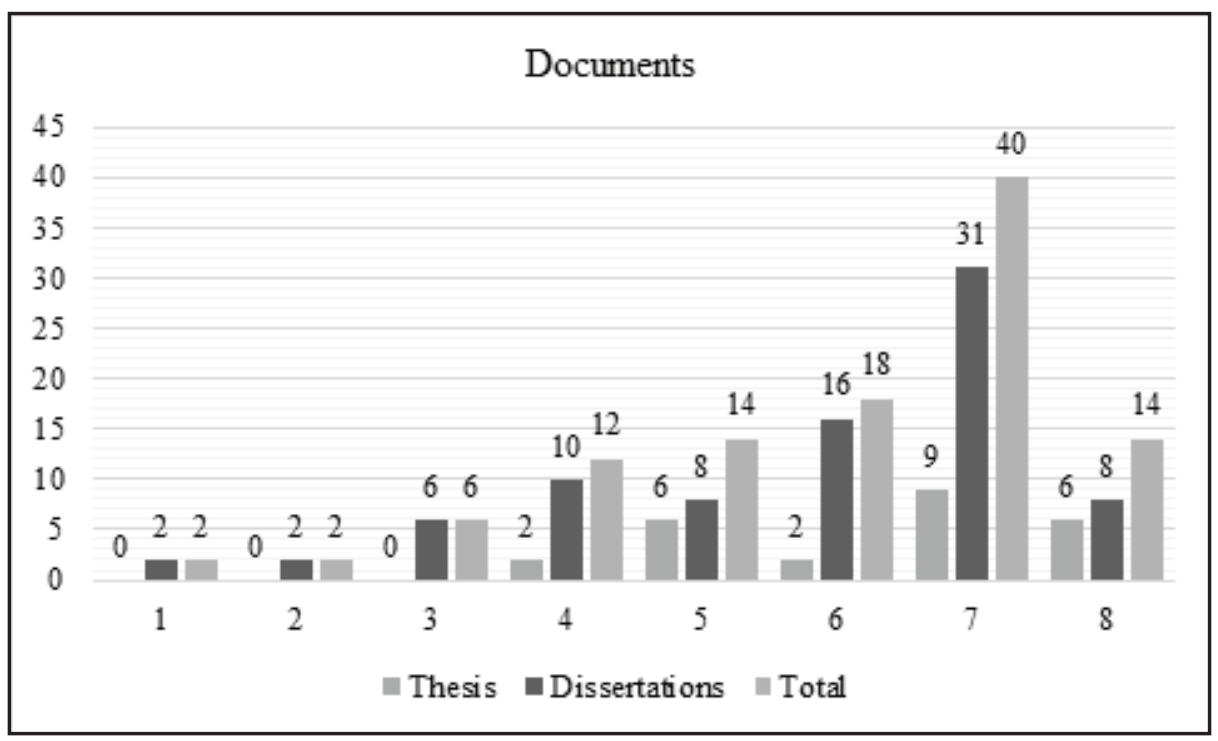

Figure 2 - Number of publications per year

The first documents are dated to the year 2013. Within Brazil, Albuquerque's dissertation (2013) analysed, from a case study, how actors act in the recycling chain in the city of Rio de Janeiro. Articulation aspects of the actions adopted in the post-consumption stage in the city were explored in conjunction with actions at the state and country level. Another pioneering study was developed at the University of Utrecht, in the Netherlands, authored by Damen (2013). The dissertation, linked to the Sustainable Development Program, addresses the issue of scarcity of resources applied to the micro level of the circular economy. The format and the possibility of allocating resources are defined as a tool to manage the scarcity of resources towards the definition of management and production guided by the insertion of the circular economy.

Theses and dissertations show an increasing trend over time. The year 2019 has the highest frequency, with 9 theses and 31 dissertations, in 40 documents. This indicates that the academy is devoting more and more attention to educating new scientists with a focus on the topic to keep up with advances in organizations and governments. Only for the year 2020 that is still ongoing, there are 14 documents. The production of theses and dissertations are the 
result of an improved knowledge-building process aimed at specialized training. The growth of documents published with this profile is an important step towards advancing this field of knowledge.

\section{THEMATIC ANALYSIS}

The results of the literature review indicate the concentration of studies in groups and subgroups of interest, referred to as categories and subcategories of analysis. The development and interpretation of results are comprised of 11 predominant categories and 5 subcategories, arranged and coded in Figure 03.

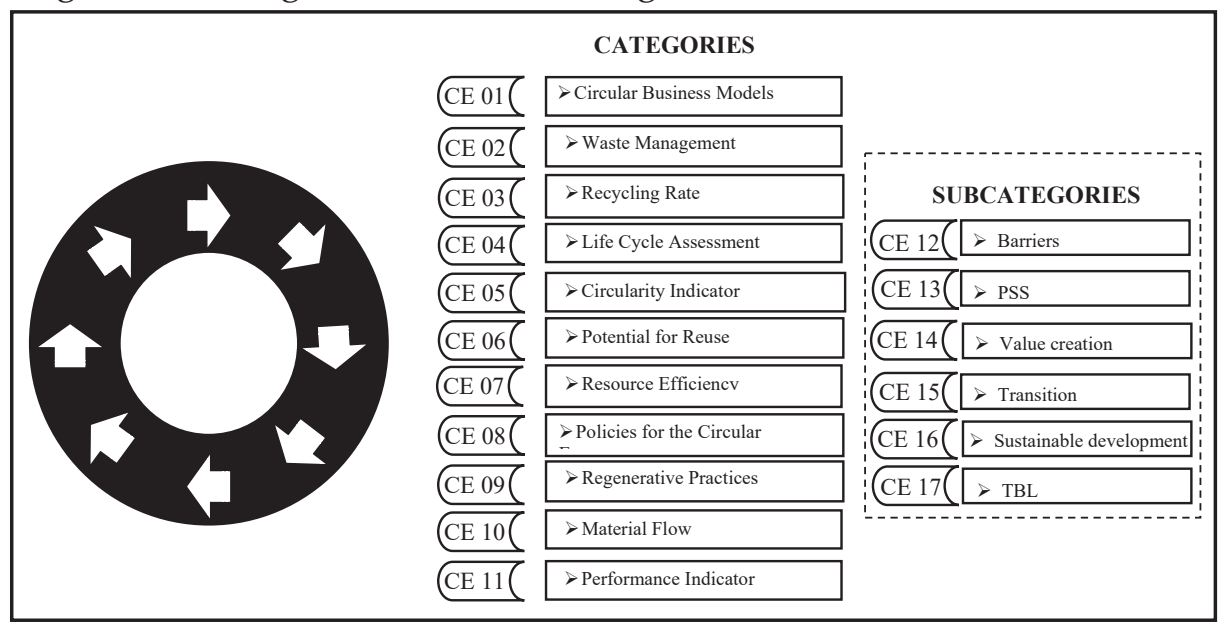

Figure 03 - Analysis Categories and Subcategories

The categorized thematic areas are analysed in view of the different interactions that research produces, defined from theoretical elements previously identified in the literature. The themes are presented in section 5.1 to 5.12, considering the arrangement ordered according to their recurrence in the studies, as follows: 5.1 Circular Business Models, 5.2 Waste Management, 5.3 Recycling Rate, 5.4 Life Cycle Assessment, 5.5 Indicator Circularity, 5.6 Reuse Potential, 5.7 Resource Efficiency, 5.8 Circular Economy Policies, 5.9 Regenerative Practices, 5.10 Material Flow, 5.11 Performance Indicator, and 5.12 Circular Economy Subcategories, with the themes of Barriers, Product-Service System, Value Creation, Transition to Circular Economy, Sustainable Development and Triple Bottom Line. 


\subsection{Circular Business Models}

The Circular Business Model category includes the discussion on the emergence of the formation of business models aligned with the principles of circular economy (Geissdoerfer et al., 2017). The proposition of differentiated forms of business implies not only a change in the way it is produced, but above all in how the operational models are configured, in the relationships between links in a supply chain and in innovation systems that encourage the incorporation of best practices for the circular economy (Rossi et al., 2019). The paradigm shift resulting from the transformation of the production logic to a closed-loop system demands the redesign of the design of products and processes to enable the triggering of the appropriate actions for the circularity of material and reduction of energy loss through entropy (Lieder, Asif, \& Rashid, 2020). Therefore, it is necessary to innovate to incorporate the concepts of CE in business (Salvador et al., 2020).

The model proposed by the Ellen MacArthur Foundation translates these elements into operational principles, which comprise six managerial actions for the business: regenerate, share, optimize, cycles, virtualize and exchange (EMF, 2015). The ReSOLVE model is a practical and applicable alternative to guide companies with circular strategies, fostered by innovation and adapted to a growth scenario. For the refinement of business models oriented towards the circular economy, Lüdeke-Freund, Gold and Bocken (2018) develop an analysis in order to define the main dimensions and characteristics. The analytical structure on business models implies the commitment to propose, create and capture value, which are based on opportunities for narrowing, decelerating and closing material cycles.

\subsection{Waste Management}

The Waste Management category presents studies on the possibilities of efficient treatment of production waste or human activity and its transformation into productive resources (Parajuly et al., 2020). While the environment provides resources, it is also a waste assimilator. The principles of circular economy imply taking waste as an alternative source of resources (Acerbi \& Taisch, 2020). 
It is not just a matter of reducing production waste, but mainly of creating value by reincorporating it into the production system (Chen et al., 2020). In addition to reducing externalities by reducing waste, it also allows production cycles to be fed back with materials already removed from the environment. Therefore, in the circular logic of production, what used to be waste must be considered as raw material for other products, maintaining a closed production circuit (Haupt \& Hellweg, 2019).

Waste management is a sustainable alternative to balance the consumption of natural resources and the reincorporation of resources in the production system and in nature. It is a tool for the management of materials in a dynamic system of transit resources (Parajuly et al., 2020). At the same time, in line with the social principles of sustainability, it allows the creation of green jobs and income generation for the actors involved in the process. The action, although inherent to the performance of company managers and government agents, demands community awareness about the preservation of resources, since it is necessary to incorporate ecological values and consumption behaviour in society (Kuzmina et al., 2018).

\subsection{Recycling Rate}

The Recycling Rate category contributes to the reinsertion of materials in the production cycle and reduces the environmental burden of disposal (Fellner \& Lederer, 2020). Among the main possibilities of value creation related to the circular economy are those based on down cycling and upcycling, which consist in recovering or increasing the value of previously discarded materials. It is common for these practices to be suitable for the reincorporation of materials at the beginning or at the end of the supply chain, that is, close to the inputs and outputs of materials (Lüdeke-Freund, Gold, \& Bocken, 2018).

The gain of materials that can be fully reincorporated into production cycles by recycling reduces the burden of extracting virgin material from the medium. The other activities of repair, remanufacturing and extending the useful life of products and components are associated with recycling as a form of continuous closure of production cycles (Fellner \& Lederer, 2020). The narrowing of resource 
loops, with less consumption of resources and reduction of energy loss are latent principles of the circular economy. The articulation of different strategies allows the potentialization of effects and value gain, according to the possibilities of each product and component (Sartal, Ozcelik, \& Rodríguez, 2020).

\subsection{Life Cycle Assessment}

The Life Cycle Assessment (LCA) category is the basis for implementing circularity in products and materials, by proposing a consistent and results-oriented system for identifying possibilities for closing cycles (Kambanou \& Sakao, 2020). For all products, results of manufacturing processes, strategies can be outlined to slow down the loss of value from the study of the stages of production, use and disposal. LCA is a widely used methodology as a tool to measure the possibilities of inserting circular elements into the production process (Primc et al., 2020). By assessing the stages of production and use of products and components, it is possible to plan and propose actions to reduce pressures on products, outline strategies for reuse, reconditioning, recomposition and remanufacturing. The evaluation of the production and use cycle is a tool to provide sufficient information to establish parameters between products, compare and improve them (Souza Junior et al., 2020).

Life cycle assessment in line with the principles of the circular economy allows strategies to be proposed for each stage of production and consumption. The actions are applicable to other circular premises, such as reuse, recycling or incineration (Kambanou \& Sakao, 2020). For open strategies, such as recycling, products can be evaluated for reinsertion in the manufacture of other products, or for incorporation into the same product system. In all cases, possibilities for improvement can be traced to minimize the loss of material or energy (Hoffmann, Morais, \& Teodoro, 2019).

\subsection{Circularity Indicator}

The Circularity Indicator category is taken as the ratio between the economic value of each recirculated session and the economic value of all parts of the process (Linder et al., 2020). Broadly speaking, circularity indicators aim to measure the level of circularity 
of products, components and materials, as well as the possibility of restoring flows and limiting energy loss (EMF, 2015). The different indicators can be dimensioned in groups that explore the micro (product, component, material, energy, consumers), meso (industrial parks, clusters, supply chain) or macro (city, province, country, governments) levels. They can be guided by different purposes, such as measuring economic value, conservation of materials and energy, resource flows, among others.

The Material Circular Indicator (MCI) proposed by the Ellen MacArthur Foundation, taken as an example, can be applied at the product level and corporate level. It allows to compare how circular a product is, taking as reference its permanence of use or prolongation of use, and how circular are products within the same portfolio, from a comparative point of view (EMF, 2015). The fundamental premise of the model is the combination of the product's own elements, such as mass of virgin resources incorporated in the manufacture, mass of resources that cannot be recovered by the product's manufacturing activity and a given utility factor that consists of the intensity of durability of the product. use. With the application of $\mathrm{MCI}$, a product that uses only virgin resources and that the end of use is intended for disposal, is considered to be completely linear. In the opposite context, with the use of recycled material and with destination after use for the total reuse of the components, the product is evaluated as fully circular. In the practical application of the indicator, the possible evaluated products are arranged between the ends, varying in a classification that is between 0 and 1 . Like the mentioned indicator, other tools can provide more or less objective criteria for evaluation (EMF, 2015).

\subsection{Potential for Reuse}

The Potential Reuse category deals with the level of implementation of the reuse of materials and inputs in the circular production process, making the constant re-entry of materials through the reuse of components (Park \& Chertow (2014). Circular business models allow and encourage continuous reuse of components and materials. The reinsertion of products allows the extension of utility and added value through use. The narrowing of material loops, with 
the objective of closing production cycles and reducing material outflows is an effort that gains potential at each possibility of reinserting components into the production system (Sartal, Ozcelik, \& Rodríguez, 2020). An upward potential for reuse implies minimizing energy loss through processing, as well as the circular trajectory of materials, fundamental premises of the circular model. different strategies for closing loops or slowing down loss of utility (Hussain \& Malik, 2020).

The reuse of components and products can be enhanced by running shorter cycles. Shorter use cycles mean fewer exchanges for reuse, and therefore less products are used. In this sense, it is more efficient to prioritize internal cycles, associated with smaller exchanges, than external cycles, in which products go through more intense stages of transformation, as in the case of recycling (Lüdeke-Freund, Gold, \& Bocken, 2018).

\subsection{Resource Efficiency}

The Resource Efficiency category deals with the optimization and maximization of the use of materials and energy (Di Maio et al., 2017). In a context of consolidating sustainable and circular practices, the way companies use resources with a focus on efficiency is fundamental (Bracquené, Dewulf, \& Duflou, 2020). The optimized and conscious use of resources, the management of their flows and use for the purpose of extending utility is enhanced in a global context of constant growth in demand with a reduced and finite disposition of resources. The growth guided by sustainability involves the efficient management of available resources, the prolongation of their use and respect for the limits of exploitation that the planet supports. Technological advances allow losses of value and resources along the supply chain to be reduced or eliminated through the incorporation of practices aligned with circular principles (Julianelli et al., 2020).

Decision-makers and policymakers have the arduous task of articulating the efficient use of resources with improving performance through their use (Slorach et al., 2020). The scenario demands the proposition of indicators capable of describing the situation and drawing alternatives through the provision of opportunities for 
leverage through reduction, reuse and recycling. The limits for the implementation of actions in a circular economy are imposed by the efficiency in the arrangement of resources. The more deficient the use of the resource, the more difficult it will be to obtain results.

\subsection{Policies for the Circular Economy}

The category Policies for the Circular Economy inserts the theme in the context of government regulations, incentives and actions so that the circular economy is incorporated at different levels in society (Silvestri, Spigarelli, \& Tassinari, 2020). Regulatory policies determine responsibilities and set goals for different sectors as a joint effort to achieve them. Government initiatives to develop and implement strategies for the transition to the circular economy can be found all over the planet (Avdiushchenko \& Zając, 2019). The transition will only have a consolidated effect if it relies on the collective effort and connection between sectors. Therefore, the registration of successful actions helps to foster and stimulates the building of an international scenario regarding the implementation, evolution and consolidation of the circular economy on government agendas (Slorach et al., 2020).

The reconfiguration of business models requires systematic change and innovation to incorporate new production patterns. Policies to encourage circular transition need to encourage the restructuring of value chains so that differentiated production and management models can generate ways to transform waste into resources and optimize their use (Hanumante, Shastri, \& Hoadley, 2019). The transposition of the linear production model requires that the planning be transversal across the various sectors, based on policies to promote change and stimulate action. The transformation of the economic model should be a source of encouragement for circular logic to be disseminated to the smallest links in the production chain and encourage the adoption of more conscious consumption behaviour patterns.

\subsection{Regenerative Practices}

The category of Regenerative Practices comprises the continuous progression towards adopting restorative and reconciling actions for 
production systems in circular logic (Lütje \& Wohlgemuth, 2020). Combined with the other principles of the circular economy, regenerative progression results in lower levels of demand for external resources and in the longevity of cycles (Zhou et al., 2019). Unlike the circular production system, linearity is degenerative in its essence, since the flows of resources and energy are not fed back by the system itself. The end of use implies disposal and loss of the resource as a final measure (Zhou et al., 2020). The resources enter a flow whose result is the waste of assets and the underutilization of materials. This model reduces the potential for use and generates economic and socio-environmental externalities derived from the production process.

The incorporation of regenerative practices improves natural capital through controlled consumption of resources and the extension of their usefulness, interspersed with the insertion of resources from renewable sources whenever possible. Through product dematerialization and use of services, use of renewable resources in production processes, reconditioning, regeneration and recovery of products and components, production cycles receive less pressure and natural systems are less impacted by industrial activity (Sartal, Ozcelik, \& Rodríguez, 2020). In addition to the possibility of impact reduction, a means must be sought to effectively become a symbiotic part of nature and its resources (Haupt \& Hellweg, 2019). In a fully regenerative state, production loops are designed to support the maximum extent of use with the least impact on the natural environment. The Ellen MacArthur Foundation (EMF, 2015) encourages the incorporation of diversity, the use of non-toxic biological resources, the use of systemic thinking, the encouragement of solving engineering and business challenges and the leverage of collaborative systems as a guarantee for the possibility of regeneration in the context of the circular economy.

\subsection{Material Flows}

The Material Flow category enables companies to adopt practices that maximize the use of resources originating from regenerative processes, reducing the entry of new raw materials (Saidani et al., 2019). Based on the mapping of material flows and procedures, op- 
timization, recycling and rationalization measures can be designed for each part of the production process. The logic of understanding material flows in industry derives from the incorporation of elements inherent to the dynamics of nature. In the natural system, resources and energy are used and reused in a constant and uninterrupted flow, in which externalities and waste are not generated. Material consumption is highly optimized and recirculation occurs with minimal losses, in a fluid system. In the industrial system, the understanding of resource flows demands that the losses of raw materials and energy are minimal made possible mainly due to the recovery and reuse of every component (Slorach et al., 2020).

The main barrier to the complete optimization of material flows is dysfunctions in the relationship between products and suppliers. The ideal scenario for the incorporation of optimized flows implies the execution of cooperative processes between partners in a supply chain, so that waste from a process can easily be incorporated into other production processes (Guldmann \& Huulgaard, 2020). The value of the materials is retained in the product and losses are avoided. The quality of material flows has an impact on the different elements of the production chain and is reflected in mutual environmental benefits. The evaluation of material flows to correct inconsistencies and improve processes is relevant to enhance circular performance (Sassanelli et al., 2019).

\subsection{Performance Indicator}

The Performance Indicator category finds definition in the ratio between real environmental performance and ideal environmental performance, in the form of obtaining mutual gains and benefits in the relationship between companies versus natural environment (Huysman, et al., 2017). The performance theme is widely studied and consolidated in the management and business study area (Gruman \& Saks, 2011). It is taken in studies of the area as a dependent variable, in which different elements exert influence and conditioning power in the form of a dependency relationship. For different analysis parameters, different measures or results for performance can be generated (Sassanelli et al., 2019). In the context of the circular economy, performance is measured according to specific 
conditions, in order to measure values and practices or the results of actions geared to circularity. As in the field of sustainability, the achievement of performance is conditioned to the criterion to which the analysis is linked and the unit to which the study applies (Alexander, 2020).

Performance measurement, in the context of the circular economy, is linked to the longevity of use or duration of a resource in the cycle (Franklin-Johnson et al., 2016). The longevity indicator is associated with environmental performance, which refers to how extensive the usefulness of a material, component or product can be until rework is required for new use. The metric allows verifying the contribution so that the resources are retained and kept fully in use. In a perfectly circular system, the utility of use tends to infinity (Buonocore et al., 2019). A product with a longer service life is more in line with the principles of circular economy than one with less usage time. The continued use of the product implies a reduction in the need for new products.

\subsection{Subcategories of Circular Economy}

Other topics were addressed in the context of application and implementation of the circular economy at different levels, from the micro to the macro aspect. These themes register less frequently in relation to the others already discussed, but involve contribution and progress towards the incorporation of the theme in different areas.

The subcategory of barriers adds contribution in the field by exploring themes that hinder or delay the incorporation of the circular economy in companies and in the agenda of policy makers (Guldmann \& Huulgaard, 2020). The circumvention of barriers and the empowerment of motivators can accelerate the transformation of the economy towards the end of production cycles. The overcoming of barriers can be operated by collecting accurate information and data regarding the different cycles of materials and products, which even allow the survey of the costs and benefits of their implementation at the sectoral level.

The Product-Service System (PSS) is treated to enable the reduction of environmental impacts by reducing the consumption of resources by prolonging the use of products. Use is not conditio- 
ned on possession, but on payment for use (Fernandes et al., 2020). Among other benefits, the reduction in the extraction of virgin materials and the generation of waste and externalities are inherent to the PSS, which imply an increase in efficiency and in the value of the product (Bansal et al., 2020). Companies are given the business opportunity to design and develop products that meet the needs of consumers while prolonging relationships. The topic is potentially promising as a way to facilitate the transformation from the traditional model to the circular economy.

The subcategory of value creation in the context of the circular economy is generated by the opportunity to extract value by extending the useful cycles of products and components (Nubholz, 2018). By continuously extending or reinserting materials in the production cycle, value is added through prolonged use, in the case of technical cycles, and cascading use, in biological cycles (EMF, 2015). Therefore, value is created by further exploring the value retained in products by closing the use of resources in cycles, which additionally allows to conserve energy and reduce its loss in manufacturing (Linder et al., 2020).

The transition to the circular model is a topic addressed holistically in studies of circular economics (Boer et al., 2020). It implies the gradual and continuous implementation of the principles inherent in the "reduce to add" philosophy. The transition to CE requires engagement, transformation, innovation and change in tractionary models. It aims to incorporate the fundamental notion that it is necessary to establish real conditions for life on the planet by respecting its limits and promoting respect for the natural environment (Chen et al., 2020).

The subcategory called sustainable development comprises the articulation of actions and the production of effects through the incorporation of CE's own principles as a means to achieve a form of development aligned with the principles of the planet's sustainability (Svenfelt et al., 2019; Chen et al., 2020). Although described as a subcategory, the theme of sustainable development is broader and explored theoretically than CE (Silvestri, Spigarelli, \& Tassinari, 2020). Closing production cycles is a way of making elements practical so that anthropic action is less aggressive to the environment and more aligned to the creation of conditions for sustainability. 
The Triple Bottom Line subcategory aligns the discussions on circular economy and sustainability (Kravchenko, Pigosso, \& McAloone, 2020). The incorporation of sustainability in decision making and policy formulation implies the consideration of the social, environmental and economic dimensions. The lack of articulation between the different dimensions and the practices of circular economy is cited as a weakness, especially with regard to the social aspect (Mesa, Esparragoza, \& Maury, 2018). For both themes to be aligned, it is necessary to consider an operational logic that integrates the different dimensions.

\section{DISCUSSION OF RESULTS AND PROPOSITION OF THE INTEGRATED FRAMEWORK OF CIRCULAR ECONOMY}

A systematic approach to the integration of different initiatives to promote the circular economy guarantees more promising results than isolated actions in the same context (Kristensen \& Mosgaard, 2020). The creation of value by extending the usefulness of resources can be extended by the supply chain to obtain even higher performance. Closing production cycles and eliminating waste generation also finds an improvement in efficiency when material flows within the company and between companies dependent on the same resources are rationalized (Julianelli et al., 2020). Therefore, the effective transition to a circular economy necessarily implies the integration between different links to obtain more promising results.

The incorporation of the circular economy in the agendas of decision makers requires initiatives that produce results that foster emerging practices in different fields, such as environmental, social, economic, institutional, technological, commercial (Škrinjarić, 2020). The proposition of innovative business models and engineering processes aligned with circular principles, in addition to being necessary to advance the implementation of answers to questions of a socio-environmental nature, also enables innovation and evolution in the way man relates to the environment and in how it produces its livelihoods (Linder et al., 2020). The flow of resources, in this context, does not proceed for disposal in the post-use stage, but for the perpetuation of its use in cycles.

The interface between the principles of circular economy and the assumptions of sustainability allow the combination of alterna- 
tives for socio-environmental and economic progress (Pieroni et al., 2019). The experimentation of new business models is supported by an approach widely disseminated by sustainability initiatives (Bansal et al., 2020). The structuring of the basic assumptions underlying the circular logic of economics are explored in the revised theses and dissertations. The field is promising and arouses growing interest on the part of researchers, especially in the last five years. The diversity of methodologies and forms of research development alert to the need for attention regarding systemic aspects, as well as the criteria of validity and reliability, especially in the case of emerging phenomena.

The framework presented in Figure 04, arranged below, organizes and synthesizes the key themes that are explored in the context of the circular economy based on studies of theses and dissertations. The themes are adjusted at the macro, meso and micro levels of the circular economy (Ghisellini et al., 2016; Saidani et al., 2019). The categories and subcategories are adjusted to represent the main elements that make up the theoretical construct.

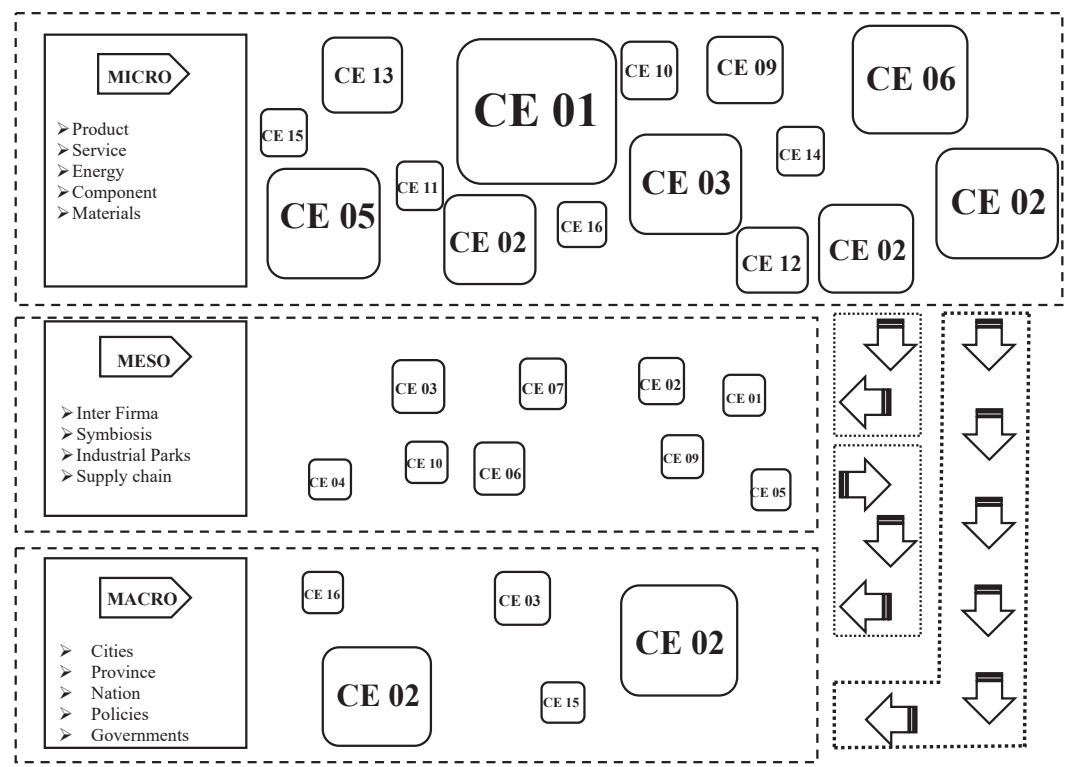

Figure 04 - Integrated Framework for Circular Economy 
Studies are predominant at the micro level, which includes exploring topics related to products, services, energy, components and materials. The micro level is related to circular economy actions operated in companies and focused on consumers. In this sense, the main mapped category is that of circular businesses. The implementation of strategies and business modification due to circularity is a basic premise for incorporating the theme in companies. Business models are described as vehicles for innovation towards the circular economy. The configuration of the business model determines the logic with all other operations to be carried out in the company to promote the closing of cycles, the retention and creation of value. Of the other categories, life cycle assessment and circularity indicators are also widely explored as tools for CE. Both themes refer to technical aspects essential to the measurement of effects and performance. Life cycle assessment allows to outline strategies for each stage of production and use of products, which makes it possible to plan the use and disposal of resources. The circularity indicator shows the level of incorporation and the trend towards the closure of production cycles compared to the linear counterpoint.

Research derived from the meso level of the circular economy extends the study of its effects beyond the context of the company, involving value chains, inter-firm relations, industrial parks, clusters and industrial symbiosis effects. This dimension is the one with the least number of researches, which demonstrates the existence of great potential to be explored. The studies are primarily focused on resource efficiency, waste management and potential for reuse. The logic of recording the frequency is valid, since these categories are the ones that most allow the transposition of value between firms. Efficiency in the use of resources, when operated along the supply chain, generates cascading gains for the various commercial links. The potential for reuse and the management of waste refer to a similar logic. The waste derived from an industrial process is no longer effectively waste when it is incorporated into another production process, which guarantees the creation of value by maintaining the resource in the production cycle. In the case of reuse, the principle is the same. It is not always possible to reuse components or materials for the same process. In this way, the commercial partnership generates mutual gains. 
The theses and dissertations focusing on the macro level (cities, provinces, nation, government, policies) explore the progression of the theme in the broadest aspect, through the proposal of regulations and actions of greater impact. The main thematic axes are focused on policies aimed at the circular economy and waste management. The focus on policies reinforces the intention of governments to make the economy more circular, and promotes it by implementing regulations that assign responsibilities and goals to different sectors of society. In fact, the circular transition is not a task for either company, but for the articulation of sectors and governments with a common goal. The assignment of goals directs each link to its respective responsibility, which allows to identify and correct dysfunctions more quickly. The topic of waste management applied at the macro level highlights the action in circular economy for a theme that has effects beyond the environmental aspect, encompassing the impact on public health of the treatment and recovery of waste.

Given the configuration of the surveys, it can be said that different areas of interest are concentrated in different lines of confrontation of the questions directed to the circular transition. Advancement at different levels is encouraged by areas of interest that share common objectives, but that outline strategies with their own means of development. Process improvements for closing production cycles, prolonging use and adding value derive from engineering and product design improvements. The innovations and changes in the business models necessary to modify the logic of the ventures are reinforced by the areas of management and business knowledge. The fundamental assumptions and principles that guide business and processes are fostered by studies of specific areas of interest to sustainability and sustainable development. Therefore, the thematic configuration and scientific and practical progress, derived from specialized researches resulting from master's and doctoral degrees, reflect the interdisciplinary effort of science to promote progress to improve the practice.

The approach of themes derived from the theoretical field, with the formulation of advances and technical improvement, especially in the case of studies applied to the resolution of practical questions, enables ways of obtaining results for companies and governments. 
The configuration present in research, in which the absence of consolidated scientific theory is predominant, directs to the treatment of fundamental changes in product and business standards. Conceptual increments imply projections to guarantee the generation of long-term capacities and preservation of the economic and environmental value of resources and energy.

Although latent, the interface between the circular economy and adjacent constructs, such as sustainability and sustainable development, was not developed as an element of centrality in research. In the field of circular economy, principles and assumptions are reflected in sustainable business models and are supported by methodologies and practices. Although there are substantial similarities in the scope that each construct disseminates, as well as differences in the centrality and dimensioning of the theme, the research does not prioritize common results for the fields. Both sustainability and sustainable development are areas of study that are more structured and that have greater clarity about what is and what is not characteristic of their constructs. However, it is noticeable that the circular economy is a field of experimentation and that it is advancing at a fast pace, but remains a diffuse concept. This is more evident in the context of companies, where many implications of the circular economy focus on one or a few activities, which can make it difficult to make inferences about "being sustainable". Actions for the circular economy, although consistent and measurable in terms of performance and circularity, can be questionable as elements of promoting sustainability in its broad and unrestricted sense.

\section{FINAL REMARKS, CONTRIBUTIONS AND LIMITATIONS OF THE RESEARCH}

Scientific contributions in the field of circular economy have evolved substantially in recent years towards obtaining support for the consolidation of the field. The specialized scientific productions, results of work and research reports of master's and doctorate, provide information on several fronts and different areas of knowledge. This systematic review, developed with the aim of verifying which existing targets and what advances the specialized research in circular economy, restricted to theses and dissertations, provide for the 
advancement in the field, brings contributions to the understanding and deepening of the topic as a promising research area.

Mapped 11 categories and 5 subcategories that group the research of theses and dissertations with a focus on circular economy. The thematic axes are segmented in several aspects and summarized as to the objectives, main results and theoretical and practical contributions to provide an overview that describes the organization of the different subjects. The central themes in studies on circular economy are associated with the following topics: i) Circular Business Models, focused on creating or improving business management and conduct practices, ii) Waste Management, associated with the reduction, reuse in product processes or elimination of tailings, in the context of companies and governments, iii) Recycling Fee, aimed at the reinsertion of materials and resources in the production cycles, iv) Life Cycle Assessment, for verification and planning of the possibilities of extending the use of resources and aggregation of value, v) Circularity Indicator, aimed at measuring results and verifying circularity levels, vi) Reuse Potential, which consists of making it possible to prolong the use of resources through reuse, vii) Resource Efficiency , which aims to rationalize and maximize the value of the resource through use, viii) Policies for the Circular Economy, directed to the formulation of reg ululation and attribution of responsibility, ix) Regenerative Practices, associated with the potential for regeneration in the closing of production cycles, $\mathrm{x}$ ) Material Flow, to verify the possibilities of identifying points of loss or reinsertion of resources, and xi) Performance Indicator, taken as a result measurement tool. The different study themes are part of a broader context, which summarizes the initiatives and work fronts studied for the transition from the economy to circularity, closing production cycles, adding value and extending the usefulness of resources.

\subsection{Theoretical Contributions}

This study contributes to the theory by mapping, describing and logically organizing the thematic routes and axes that the theses and dissertations take when describing and addressing different research problems associated with circular economics. The fundamental categories that summarize the efforts of masters and 
doctoral students regarding the understanding and exploration of the theme are analysed as a way to outline a panorama of progress in the area. The categorization and systematization of the studies resulted in guiding fields that support the development of future studies in circular economics. Especially for researchers in training, it is important to define assertive paths to guide the steps in order to guarantee the effective contribution of their research. In the methodological aspect, the framework classifies and categorizes the study axes for structuring new research insights. Given the high dynamics and constant advances that the circular economy undertakes in short periods, starting a research based on this framework allows speeding up the process of collecting previous studies.

\subsection{Practical Contributions}

From a practical point of view, this study can assist decision makers and policy makers in raising awareness and knowledge about possible fields of action regarding the implementation of the circular economy. The themes and their articulation can be taken as a basis for surveying opportunities for improvement, in order to stimulate the development and incorporation of circular practices. It is an opportunity for companies, universities and governments to explore the development of researchers and professionals to address specific and necessary aspects for the circular transition. Micro, meso and macro themes can be segmented in future projects based on consideration and affinity with each other.

\subsection{Limitations and Recommendations}

The review is based on data from only two sources (Google Scholar and BDTD), which can compromise the variability of the information. Second, the option to use only gray literature, restricted to theses and dissertations, is a conditioning factor for the generation of possible research bias. However, the procedure is justified and justified as a methodological choice for researchers. Although the documents are evaluated and placed under consideration by evaluation processes, they cannot be considered as peer-reviewed literature. Finally, the classification proposed by the authors in categories and subcategories may be compromised by their judgment, given the 
need to read, search and interpret the data for the development and classification of studies. It is recommended that in future research the categories go through a process of content validation based on the evaluation of specialists in the subject.

\section{REFERENCES}

Acerbi, F., \& Taisch, M. (2020). A literature review on circular economy adoption in the manufacturing sector. Journal of Cleaner Production, 123086. doi:10.1016/j.jclepro.2020.123086

Albuquerque, T. L. M. (2018). Análise dos custos e externalidades no contexto da economia circular. Dissertação de Mestrado, Centro Universitário FEI, São Bernardo do Campo, Brasil.

Alexander, R. (2020). Emerging roles of lead buyer governance for sustainability across global production networks. Journal of Business Ethics, 162(2), 269-290. doi: 10.1007/s10551019-04199-4

Avdiushchenko, A., \& Zając, P. (2019). Circular Economy Indicators as a Supporting Tool for European Regional Development Policies. Sustainability, 11(11), 3025. doi:10.3390/su11113025

Bag, S., \& Pretorius, J. H. C. (2020). Relationships between industry 4.0, sustainable manufacturing and circular economy: proposal of a research framework. International Journal of Organizational Analysis. doi: 10.1108/IJOA-04-2020-2120

Bansal, S., Jain, M., Garg, I., \& Srivastava, M. (2020). Attaining circular economy through business sustainability approach: An integrative review and research agenda. Journal of Public Affairs. doi:10.1002/pa.2319

Bocken, N. M., De Pauw, I., Bakker, C., \& Van Der Grinten, B. (2016). Product design and business model strategies for a circular economy. Journal of Industrial and Production Engineering, 33(5), 308-320. doi: 10.1080/21681015.2016.1172124.

Boer, D., Segarra, M., Fernández, A. I., Vallès, M., Mateu, C., \& Cabeza, L. F. (2020). Approach for the analysis of TES technologies aiming towards a circular economy: Case study of building-like cubicles. Renewable Energy, 150, 589-597.

Bracquené, E., Dewulf, W., \& Duflou, J. R. (2020). Measuring the performance of more circular complex product supply chains. Resources, Conservation and Recycling, 154, 104608. doi:10.1016/j.resconrec.2019.104608

Buonocore, E., Paletto, A., Russo, G. F., \& Franzese, P. P. (2019). Indicators of environmental performance to assess wood-based bioenergy production: A case study in Northern Italy. Journal of Cleaner Production, 221, 242-248. doi:10.1016/j.jclepro.2019.02.272

Chen, T.-L., Kim, H., Pan, S.-Y., Tseng, P.-C., Lin, Y.-P., \& Chiang, P.-C. (2020). Implementation of green chemistry principles in circular economy system towards sustainable development goals: Challenges and perspectives. Science of The Total Environment, 136998. doi:10.1016/j. scitotenv.2020.136998

Damen, M. A. (2013). A resources passport for a circular economy: An assessment of the possible content and format of a resources passport in order to successfully contribute 
to the achievement of the circular economy. Master's Thesis, Utrecht University, Utrecht, Netherlands.

Di Maio, F., Rem, P. C., Baldé, K., \& Polder, M. (2017). Measuring resource efficiency and circular economy: A market value approach. Resources, Conservation and Recycling, 122, 163-171. doi:10.1016/j.resconrec.2017.02.009

Ellen MacArthur Foundation. (2015). Towards a circular economy: Business rationale for an accelerated transition.

Fellner, J., \& Lederer, J. (2020). Recycling rate-The only practical metric for a circular economy?. Waste Management, 113, 319-320. doi: 10.1016/j.wasman.2020.06.013

Fernandes, S. C., Pigosso, D. C., McAloone, T. C., \& Rozenfeld, H. (2020). Towards product-service system oriented to circular economy: A systematic review of value proposition design approaches. Journal of Cleaner Production, 257, 120507. doi: 10.1016/j.jclepro.2020.120507

Franklin-Johnson, E., Figge, F., \& Canning, L. (2016). Resource duration as a managerial indicator for Circular Economy performance. Journal of Cleaner Production, 133, 589-598. doi:10.1016/j.jclepro.2016.05.023

Geissdoerfer, M., Savaget, P., Bocken, N. M., \& Hultink, E. J. (2017). The Circular Economy-A new sustainability paradigm?. Journal of cleaner production, 143, 757-768. doi: 10.1016/j. jclepro.2016.12.048

Ghisellini, P., Cialani, C., \& Ulgiati, S. (2016). A review on circular economy: the expected transition to a balanced interplay of environmental and economic systems. Journal of Cleaner production, 114, 11-32. doi: 10.1016/j.jclepro.2015.09.007

Gkalfas, C. (2019). Studying the impact of a mobile application in food waste reduction, circular economy, and social interaction inside the community. Master's Thesis, Linnaeus University, Kalmar, Sweden.

Gruman, J. A., \& Saks, A. M. (2011). Performance management and employee engagement. Human resource management review, 21(2), 123-136. doi: 10.1016/j.hrmr.2010.09.004

Guldmann, E., \& Huulgaard, R. D. (2020). Barriers to circular business model innovation: A multiple-case study. Journal of Cleaner Production, 243, 118160. doi: 10.1016/j.jclepro.2019.118160

Haddaway, N. R., Collins, A. M., Coughlin, D., \& Kirk, S. (2015). The role of Google Scholar in evidence reviews and its applicability to grey literature searching. PloS one, 10(9), e0138237. doi: 10.1371/journal.pone.013823

Hanumante, N. C., Shastri, Y., \& Hoadley, A. (2019). Assessment of circular economy for global sustainability using an integrated model. Resources, Conservation and Recycling, 151, 104460. doi:10.1016/j.resconrec.2019.104460

Haupt, M., \& Hellweg, S. (2019). Measuring the Environmental Sustainability of a Circular Economy. Environmental and Sustainability Indicators, 100005. doi:10.1016/j.indic.2019.100005

Heisel, F., \& Rau-Oberhuber, S. (2020). Calculation and evaluation of circularity indicators for the built environment using the case studies of UMAR and Madaster. Journal of Cleaner Production, 243, 118482. doi:10.1016/j.jclepro.2019.118482 
Hoffmann, B. S., Morais, J. S., \& Teodoro, P. F. (2019). Life cycle assessment of innovative circular business models for modern cloth diapers. Journal of Cleaner Production, 119364. doi:10.1016/j.jclepro.2019.119364

Hussain, M., \& Malik, M. (2020). Organizational enablers for circular economy in the context of sustainable supply chain management. Journal of Cleaner Production, 256, 120375. doi: 10.1016/j.jclepro.2020.120375

Huysman, S., De Schaepmeester, J., Ragaert, K., Dewulf, J., \& De Meester, S. (2017). Performance indicators for a circular economy: A case study on post-industrial plastic waste. Resources, Conservation and Recycling, 120, 46-54. doi: 10.1016/j.resconrec.2017.01.013

Jaeger, B., \& Upadhyay, A. (2020). Understanding barriers to circular economy: cases from the manufacturing industry. Journal of Enterprise Information Management. doi: 10.1108/ JEIM-02-2019-0047

Julianelli, V., Caiado, R. G. G., Scavarda, L. F., \& Cruz, S. P. D. M. F. (2020). Interplay between reverse logistics and circular economy: critical success factors-based taxonomy and framework. Resources, Conservation and Recycling, 158, 104784. doi: 10.1108/IJOA-04-2020-2120

Kambanou, M. L., \& Sakao, T. (2020). Using life cycle costing (LCC) to select circular measures: A discussion and practical approach. Resources, Conservation and Recycling, 155, 104650. doi:10.1016/j.resconrec.2019.104650

Kinnunen, P. (2019). Towards circular economy in the mining industry: implications of institutions on the drivers and barriers for tailings valorization. Master's Thesis, Tampere University, Tampere, Finland.

Konietzko, J., Bocken, N., \& Hultink, E. J. (2020). Circular ecosystem innovation: An initial set of principles. Journal of Cleaner Production, 253, 119942. doi: 10.1016/j.jclepro.2019.119942

Kravchenko, M., Pigosso, D. C., \& McAloone, T. C. (2020). A Procedure to Support Systematic Selection of Leading Indicators for Sustainability Performance Measurement of Circular Economy Initiatives. Sustainability, 12(3), 951. doi: 10.3390/su12030951

Kristensen, H. S., \& Mosgaard, M. A. (2020). A review of micro level indicators for a circular economy-moving away from the three dimensions of sustainability?. Journal of Cleaner Production, 243, 118531. doi: 10.1016/j.jclepro.2019.118531

Kuzmina, K., Prendeville, S., Walker, D., \& Charnley, F. (2018). Future scenarios for fast-moving consumer goods in a circular economy. Futures. doi:10.1016/j.futures.2018.12.001

Lieder, M., Asif, F. M., \& Rashid, A. (2020). A choice behavior experiment with circular business models using machine learning and simulation modeling. Journal of Cleaner Production, 120894. doi: 10.1016/j.jclepro.2020.120894

Linder, M., Boyer, R. H. W., Dahllöf, L., Vanacore, E., \& Hunka, A. (2020). Product-level inherent circularity and its relationship to environmental impact. Journal of Cleaner Production, 121096. doi:10.1016/j.jclepro.2020.121096

Lüdeke-Freund, F., Gold, S., \& Bocken, N. M. (2019). A review and typology of circular economy business model patterns. Journal of Industrial Ecology, 23(1), 36-61. doi: 10.1111/ jiec. 12763 
Lütje, A., \& Wohlgemuth, V. (2020). Tracking Sustainability Targets with Quantitative Indicator Systems for Performance Measurement of Industrial Symbiosis in Industrial Parks. Administrative Sciences, 10(1), 3. doi:10.3390/admsci10010003

Merli, R., Preziosi, M., \& Acampora, A. (2018). How do scholars approach the circular economy? A systematic literature review. Journal of Cleaner Production, 178, 703-722. doi: 10.1016/j.jclepro.2017.12.112

Mesa, J., Esparragoza, I., \& Maury, H. (2018). Developing a set of sustainability indicators for product families based on the circular economy model. Journal of cleaner production, 196, 1429-1442. doi: 10.1016/j.jclepro.2018.06.131

Mesa, J., Esparragoza, I., \& Maury, H. (2018). Developing a set of sustainability indicators for product families based on the circular economy model. Journal of cleaner production, 196, 1429-1442. doi: 10.1016/j.jclepro.2018.06.131

Morseletto, P. (2020). Targets for a circular economy. Resources, Conservation and Recycling, 153, 104553.doi: 10.1016/j.resconrec.2019.104553

Nußholz, J. L. (2018). A circular business model mapping tool for creating value from prolonged product lifetime and closed material loops. Journal of Cleaner Production, 197, 185-194. doi: 10.1016/j.jclepro.2018.06.112.

Paavola, M. (2020). Transport and mobility in an urban circular economy. Master's Thesis, Lappeenranta-Lahti University of Technology LUT, Lappeenranta, Finland.

Parajuly, K., Fitzpatrick, C., Muldoon, O., \& Kuehr, R. (2020). Behavioral change for the circular economy: A review with focus on electronic waste management in the EU. Resources, Conservation \& Recycling: X, 100035. doi: 10.1016/j.rcrx.2020.100035

Park, J. Y., \& Chertow, M. R. (2014). Establishing and testing the "reuse potential" indicator for managing wastes as resources. Journal of Environmental Management, 137, 45-53. doi:10.1016/j.jenvman.2013.11.053

Pereno, A., \& Eriksson, D. (2020). A multi-stakeholder perspective on sustainable healthcare: From 2030 onwards. Futures, 122, 102605. doi:10.1016/j.futures.2020.102605

Pieroni, M. P., McAloone, T. C., \& Pigosso, D. C. (2019). Business model innovation for circular economy and sustainability: A review of approaches. Journal of Cleaner Production, 215, 198-216. doi: 10.1017/dsi.2019.258

Pieroni, M.P.P., McAloone, T.C., Pigosso, D.C.A. (2019). Business model innovation for circular economy and sustainability: a review of approaches. J. Clean. Prod. 215, 198e216. doi: 10.1016/J.JCLEPRO.2019.01.036.

Pinheiro, E. (2020). Implementação dos princípios da economia circular em clusters de vestuário: uma proposta de modelo. Tese de Doutorado, Universidade Tecnológica Federal do Paraná, Ponta Grossa, Brasil.

Pla-Julián, I., \& Guevara, S. (2018). Is Circular Economy the key to transitioning towards Sustainable Development? Challenges from the perspective of care ethics. Futures. doi:10.1016/j. futures.2018.09.001 
Primc, K., Kalar, B., Slabe-Erker, R., Dominko, M., \& Ogorevc, M. (2020). Circular economy configuration indicators in organizational life cycle theory. Ecological Indicators, 116, 106532.

Roséen, J. (2019). Enabling Circular Economy with Digital Technology: A case study On the Swedish Online Secondhand Business Sellpy. Master's Thesis, Uppsala University, Uppsala, Sweden.

Rossi, E., Bertassini, A. C., Ferreira, C. dos S., Neves do Amaral, W. A., \& Ometto, A. R. (2019). Circular Economy indicators for organizations considering Sustainability and Business Models: plastic, textile and electro-electronic cases. Journal of Cleaner Production, 119137. doi:10.1016/j.jclepro.2019.119137

Saidani, M., Kendall, A., Yannou, B., Leroy, Y., \& Cluzel, F. (2019). Closing the loop on platinum from catalytic converters: Contributions from material flow analysis and circularity indicators. Journal of Industrial Ecology. doi:10.1111/jiec.12852

Saidani, M., Yannou, B., Leroy, Y., Cluzel, F., \& Kendall, A. (2019). A taxonomy of circular economy indicators. Journal of Cleaner Production, 207, 542-559. doi: 10.1016/ j.jclepro.2018.10.014

Salvador, R., Barros, M. V., da Luz, L. M., Piekarski, C. M., \& de Francisco, A. C. (2020). Circular business models: Current aspects that influence implementation and unaddressed subjects. Journal of Cleaner Production, 250, 119555. doi: 10.1016/j.jclepro.2019.119555

Santagata, R., Zucaro, A., Viglia, S., Ripa, M., Tian, X., \& Ulgiati, S. (2020). Assessing the sustainability of urban eco-systems through Emergy-based circular economy indicators. Ecological Indicators, 109, 105859. doi:10.1016/j.ecolind.2019.105859

Sartal, A., Ozcelik, N., \& Rodríguez, M. (2020). Bringing the circular economy closer to small and medium enterprises: Improving water circularity without damaging plant productivity. Journal of Cleaner Production, 256, 120363.

Sassanelli, C., Rosa, P., Rocca, R., \& Terzi, S. (2019). Circular Economy performance assessment methods: a systematic literature review. Journal of Cleaner Production. doi:10.1016/j. jclepro.2019.05.019

Schöpfel, J., \& Prost, H. (2020). How scientific papers mention grey literature: a scientometric study based on Scopus data. Collection and Curation. doi: 10.1108/CC-12-2019-0044

Silvestri, F., Spigarelli, F., \& Tassinari, M. (2020). Regional development of Circular Economy in the European Union: a multidimensional analysis. Journal of Cleaner Production, 120218. doi:10.1016/j.jclepro.2020.120218

Škrinjarić, T. (2020). Empirical assessment of the circular economy of selected European countries. Journal of Cleaner Production, 120246. doi:10.1016/j.jclepro.2020.120246

Slorach, P. C., Jeswani, H. K., Cuéllar-Franca, R., \& Azapagic, A. (2020). Environmental sustainability in the food-energy-water-health nexus: A new methodology and an application to food waste in a circular economy. Waste Management, 113, 359-368. doi:10.1016/j. wasman.2020.06.012

Souza Junior, H. R. A., Dantas, T. E. T., Zanghelini, G. M., Cherubini, E., \& Soares, S. R. (2020). Measuring the environmental performance of a circular system: Emergy and LCA approach 
on a recycle polystyrene system. Science of The Total Environment, 138111. doi:10.1016/j. scitotenv.2020.138111

Svenfelt, Å., Alfredsson, E. C., Bradley, K., Fauré, E., Finnveden, G., Fuehrer, P., ... Öhlund, E. (2019). Scenarios for sustainable futures beyond GDP growth 2050. Futures. doi:10.1016/j. futures.2019.05.001

Sverko Grdic, Z., Krstinic Nizic, M., \& Rudan, E. (2020). Circular Economy Concept in the Context of Economic Development in EU Countries. Sustainability, 12(7), 3060. doi:10.3390/ su12073060

Tranfield, D., Denyer, D., \& Smart, P. (2003). Towards a Methodology for Developing Evidence-Informed Management Knowledge by Means of Systematic Review. British Journal of Management, 14(3), 207-222. doi:10.1111/1467-8551.00375

Völker, T., Kovacic, Z., \& Strand, R. (2020). Indicator development as a site of collective imagination? The case of European Commission policies on the circular economy. Culture and Organization, 1-18. doi:10.1080/14759551.2019.1699092

Wang, S. (2020). Promoting a Circular Economy in the Mobile Phone Product System in China. Master's Thesis, KTH Royal Institute of Technology, Stockholm, Sweden.

Zhou, Y., Stanchev, P., Katsou, E., Awad, S., \& Fan, M. (2019). A circular economy use of recovered sludge cellulose in wood plastic composite production: Recycling and eco-efficiency assessment. Waste Management, 99, 42-48. doi:10.1016/j.wasman.2019.08.037

Recebido em: 12-5-2021

Aprovado em: 18-11-2021

Avaliado pelo sistema double blind review.

Disponível em http://mjs.metodista.br/index.php/roc 